\title{
PD-L1 gene promoter methylation represents a potential diagnostic marker in advanced gastric cancer
}

 \\ ${ }^{1}$ Dalian Medical University, Dalian, Liaoning 116044; Departments of ${ }^{2}$ Oncology and ${ }^{3}$ Pathology, \\ The Second Affiliated Hospital of Dalian Medical University, Dalian, Liaoning 116023; ${ }^{4}$ Department of \\ Obstetrics and Gynecology, The First Affiliated Hospital of Dalian Medical University, Dalian, Liaoning 116011, P.R. China
}

Received April 24, 2019; Accepted November 8, 2019

DOI: $10.3892 / \mathrm{ol} .2019 .11221$

\begin{abstract}
Gastric cancer is one of the most prevalent malignant tumors worldwide. Immunological checkpoint inhibitors of the programmed death 1 (PD-1)/programmed cell death-ligand 1 (PD-L1) signaling pathway are effective in the treatment of various malignant tumor types, but the potential of such immunotherapeutic techniques for the treatment of gastric cancer is yet to be elucidated. The purpose of the present study was to investigate the methylation of the PD-L1 gene promoter and its clinical significance in advanced gastric cancer, as this may suggest the use of PD-L1 promoter methylation as a novel biomarker for gastric cancer progression. In a total of 70 samples, the methylation rate of the PD-L1 gene promoter region was significantly higher in gastric cancer tissues compared with adjacent tissues. A high level of PD-L1 promoter methylation was associated with lymph node staging, and resulted in poorer prognoses in patients with advanced gastric cancer. A total of 26 patients exhibited highly methylated PD-L1; in this group, the median progression-free survival time of patients receiving platinum/fluorouracil chemotherapy was 4.2 months longer than those receiving paclitaxel/fluorouracil chemotherapy,
\end{abstract}

Correspondence to: Professor Tao Wu, Department of Oncology, The Second Affiliated Hospital of Dalian Medical University, 465 Zhongshan Road, Dalian, Liaoning 116023, P.R. China

E-mail: wuyihong97@163.com

Professor Na Gao, Department of Obstetrics and Gynecology, The First Affiliated Hospital of Dalian Medical University, 222 Zhongshan Road, Xigang, Dalian, Liaoning 116011, P.R. China E-mail: gaona2001@163.com

Abbreviations: PD-1, programmed death 1; PD-L1, programmed cell death-Ligand 1; MSP, methylation-specific PCR; NSCLC, non-small cell lung cancer; PFS, progression-free survival; OS, overall survival

${ }^{*}$ Contributed equally

Key words: gastric cancer, PD-L1, methylation, chemotherapeutic efficacy, prognosis and the risk of disease progression in patients receiving paclitaxel/fluorouracil chemotherapy was 5.009 times higher compared with patients who received platinum/fluorouracil chemotherapy. Additionally, PD-L1 promoter methylation was significantly correlated with PD-L1 expression, and the progression of advanced gastric cancer. In conclusion, high methylation levels of the PD-L1 promoter region may be a faciliatory mechanism enabling gastric cancer tumorigenesis, and may also represent an independent prognostic factor for chemotherapeutic efficacy in patients with advanced gastric cancer.

\section{Introduction}

Gastric cancer is a highly prevalent malignant tumor type; according to the Global Cancer Epidemiology Statistics (GLOBOCAN) (1), published in 2018, gastric cancer is the fifth most common cancer type and the third leading cause of cancer-related mortality globally. Notably, $>50 \%$ of cases occur in Asia, and the incidence in men is $\sim 2$ times that in women. Gastric cancer is highly heterogeneous and typically asymptomatic during the early stages. The majority of patients are diagnosed in the advanced stage leading to a low 5-year survival rate of $20-25 \%$ (2). Gastric cancer is also highly invasive and often results in distant metastasis. Currently, an individualized chemotherapy regime is the most common therapeutic method in patients with recurrent and unresectable advanced gastric cancer; first-line treatment consists of fluorouracil chemotherapy, combined with platinum and/or paclitaxel to form a two- or three-drug regimen. However, the median overall survival (OS) time in patients with advanced gastric cancer is just 10-15 months (3). Therefore, it is important to improve the therapeutic efficacy of treatment options, and to study the mechanisms of tumorigenesis and progression in gastric cancer.

Previous studies have determined that the occurrence and development of human tumors are associated with epigenetic alterations, which refers to reversible genetic phenotypic changes that are not caused by changes to the DNA sequence, but remain relatively stable during cell division. These heritable alterations provide an outer transcriptional control model used for the regulation of gene expression, and are implicated in tumor development and progression (4). DNA methylation 
plays an important role in epigenetics, and abnormal DNA methylation patterns may lead to transcriptional repression, cell cycle disorder, abnormal activation or inactivation of signaling pathways, abnormal apoptotic mechanisms, activation of proto-oncogenes and tumorigenesis (5-8).

Immunotherapy has gained traction as a viable treatment option for multiple cancer types. Programmed death-1 (PD-1), a member of the CD28 superfamily, is an important immunosuppressive molecule. Immunoregulatory targeting of PD-1 exhibits significant potential in tumor therapy; its ligand PD-L1 (programmed cell death-Ligand 1) is a transmembrane protein (40 kDa) that can be targeted using antibodies. Typically, the immune system responds to foreign antigens that accumulate in the lymph nodes or spleen by promoting T-cell proliferation, with antigen specificity. Tumor cells evade destruction by T-cells by expressing PD-L1 on their surface. When T-cell PD-1 recognizes its ligand (PD-L1) it transmits inhibitory signals, and hence prevents T-cell activation. PD-1/PD-L1 inhibitors block the binding of PD-1 to PD-L1, preventing negative regulatory signals and restoring $\mathrm{T}$-cell activity, thereby enhancing the immune response $(9,10)$. Currently, immunological inhibitors of PD-1/PD-L1 signaling pathway checkpoints are effective in the treatment of malignant tumors, such as melanoma, non-small cell lung cancer (NSCLC) and lymphoma (11-13). However, the potential of immunotherapy as a treatment option for patients with gastric cancer remains to be elucidated.

The purpose of the present study was to investigate the methylation status of the PD-L1 gene in the cancerous and adjacent tissues of patients with gastric cancer, alongside immunohistochemical analysis of the PD-L1 protein. The association between PD-L1 methylation patterns and clinical characteristics, chemotherapy efficacy, progression-free survival (PFS) and OS times in patients with advanced gastric cancer was evaluated.

\section{Materials and methods}

Patients and sample collection. A total of 70 paraffin-embedded tissue samples were collected from patients with advanced gastric cancer, comprised of 49 men (30-83 years) and 21 women (43-79 years), who were hospitalized at the Second Affiliated Hospital of Dalian Medical University (Liaoning, China) between January 2010 and August 2017, and were retrospectively analyzed in the present study. A total of 20/70 patients with gastric cancer were selected, and the adjacent tissues of these 20 patients were used as controls. The inclusion criteria were as follows: i) Recurrence after radical gastrectomy or palliative surgery was histopathologically confirmed as gastric cancer; ii) full follow-up data were available; iii) patients had received $\geq 2$ cycles of chemotherapy at the Second Affiliated Hospital of Dalian Medical University (Liaoning, China); iv) lesions were measured using imaging machines such as CT or MRI; and v) the Eastern Cooperative Oncology Group score was $\leq 2$ points. The exclusion criteria included: i) Patients who had previously received chemotherapy, radiotherapy and/or biological treatment at another institution; ii) patients with abnormal liver, kidney or bone marrow function; and iii) patients with other organ diseases, immune dysfunction or malignant tumors. All 70 patients were followed up via clinical visits or telephone calls; the final follow-up was conducted in January 2019 and the median follow-up time was 10.55 months. Tumor stage was classified according to the American Joint Committee on Cancer TNM staging system (7th edition). The present study was approved by the Ethics Committee of the medical university and the patients provided written informed consent.

Efficacy evaluation criteria. The majority of patients received two-drug combination chemotherapy $(n=49)$, with fewer patients receiving single-agent $(n=12)$ or three-drug combination treatment $(n=9)$. Patients that received two-drug therapy were divided into paclitaxel/fluorouracil and platinum/fluorouracil groups. Evaluation of treatment efficacy was calculated for all patients following 2-3 cycles of chemotherapy, according to the Response Evaluation Criteria in Solid Tumors 1.1 (RECIST1.1). The chemotherapy efficacy and disease control rates were calculated as [complete response $(\mathrm{CR})+$ partial response $(\mathrm{PR})] /$ total cases $\mathrm{x} 100 \%$, and $[\mathrm{CR}+\mathrm{PR}+$ stable disease (SD)]/total cases $\mathrm{x} 100 \%$, respectively.

Methylation-specific PCR (MSP). PD-L1 gene promoter methylation was detected using MSP. Genomic DNA isolation was performed on five $10-\mu \mathrm{M}$ paraffin-fixed sections using a genomic DNA extraction kit, and bisulfite-mediated DNA modification was performed using the EZ DNA Methylation Kit (both Zymo Research Corp.) according to the manufacturers' protocols. Methylation-specific primers were designed using Sequenom Assay Design 3.1 software (Sequenom) and the sequences are listed in Table I. The MSP reaction $(10 \mu \mathrm{l})$

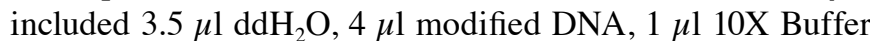
I, $0.1 \mu 1$ HsTaq DNA polymerase mixture and $0.6 \mu 1$ methylation-specific or non-methylation-specific primers.

PCR was performed using the following thermocycling conditions: $95^{\circ} \mathrm{C}$ for $5 \mathrm{~min} ; 35$ cycles of $95^{\circ} \mathrm{C}$ for $30 \mathrm{sec}, 63^{\circ} \mathrm{C}$ for $30 \mathrm{sec}$ and $72^{\circ} \mathrm{C}$ for $30 \mathrm{sec}$; followed by extension at $72^{\circ} \mathrm{C}$ for $10 \mathrm{~min}$ and storage at $4^{\circ} \mathrm{C}$. PCR products were extracted after gel electrophoresis and subsequently sequenced (Invitrogen; Thermo Fisher Scientific, Inc.). Amplification using methylation-specific primers, or a lack of amplification using non-methylation-specific primers was considered to indicate a positive result for methylation. Additionally, amplifications using methylation-specific and non-methylation-specific primers that also exhibited partial methylation were recorded as positive methylation. Results indicating negative methylation were reported when no amplification was observed using methylation-specific primers, or amplification was observed using non-methylation-specific primers (Fig. 1).

Immunohistochemistry (IHC). Immunohistochemical staining of PD-L1 was performed on $6-\mu \mathrm{m}$ formalin-fixed (at $4^{\circ} \mathrm{C}$, overnight), paraffin-embedded tissue sections using the Immunohistochemical Streptavidin-Peroxidase kit (OriGene Technologies, Inc.), according to the manufacturer's protocol. Sections were then incubated with a primary anti-PD-L1 rabbit polyclonal antibody (1:50; ProteinTech Group, Inc.; cat. no. 17952-1-AP) at $4^{\circ} \mathrm{C}$ overnight, followed by peroxidase-labeled secondary antibody (SPlink Detection Kits; pre-diluted; cat. no. SP-9001; ZSGB-BIO) staining at $37^{\circ} \mathrm{C}$ for $1 \mathrm{~h}$. Immune complexes were stained using 
Table I. Sequences and amplicon sizes of primers used for programmed cell death-Ligand 1 methylation-specific PCR.

Primer

Sequence

PCR product size, bp

Forward methylation-specific primer

Forward non-methylation-specific primer Universal reverse primer
5'-ATGTTAGGTTGGAGGTTTGGATAC-3'
5'-ATGTTAGGTTGGAGGTTTGGATAT-3'
5'-TTCC(G/A)TTCAAAAATCCTAAACCTAC-3'
141

141

N/A

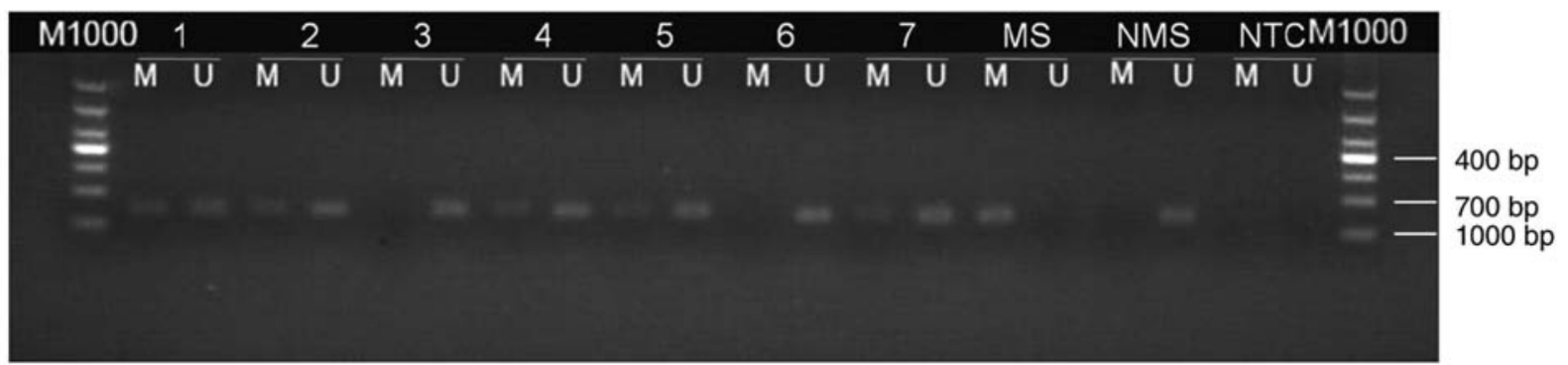

Figure 1. Representative gastric cancer samples using methylation-specific PCR assays of PD-L1. M, methylated alleles; U, unmethylated alleles; MS, methylated DNA Standard; NMS, non-methylated DNA Standard; PD-L1, Programmed cell death-Ligand 1; NTC, no template control; M1000, DNA marker.

3,3'-diamino-benzidine tetrahydrochloride (DAB) substrate at room temperature for $1 \mathrm{~min}$. Subsequently, the slides were counterstained using hematoxylin (Hematoxylin and Eosin Staining kit; cat. no. C0105) at room temperature for $1 \mathrm{~min}$ and treated with neutral balsam, according the manufacturer's protocol. Phosphate-buffered saline was used instead of the primary antibody as a negative control.

The cytoplasmic presence of pale yellow to moderate brown granules was considered to represent positive PD-L1 staining. The staining was scored and averaged by three independent clinical pathologists according to a predefined scoring system (14). Five random fields were imaged from each slide using a BX41 light microscope (Olympus Corp.) at a magnification of $x 100$. Staining was graded based on the intensity of the majority of the positively stained cells: 0 , no staining; 1, pale yellow; 2, moderate brown; and 3, dark brown. Additionally, a score was assigned based on the average percentage of positively stained tumor cells from all five fields: $0, \leq 25 ; 1,26-50 ; 2,51-75$; and $3,>75 \%$. The final score was obtained by adding the percentage score and intensity grade, and stratified as: ' - ' $=0$; ' + ' $=1-2 ;$ ' ++ ' $=3-4$; and ' +++ ' $=5-6$. The ' ++ ' and ' +++ ' groups denoted positive expression, whilst the '-' and '+' groups represented negative expression.

Statistical analysis. SPSS 22.0 (IBM Corp.) was used to perform statistical analyses. The $\chi^{2}$ test was used to compare PD-L1 methylation patterns between cancer and adjacent tissues, and the Fisher's exact test was used to determine the association of PD-L1 methylation in cancer tissues with certain clinical characteristics and chemotherapeutic efficacy. The logistic regression model was used to find predictors of chemotherapy efficacy. The log-rank test was used to compare survival times and Kaplan-Meier analysis was used to construct survival curves. Prognostic factors were analyzed by Cox's regression. $\mathrm{P}<0.05$ was considered to indicate a statistically significant difference.

\section{Results}

PD-L1 promoter methylation levels. The methylation rate of the PD-L1 gene promoter was significantly higher in gastric cancer tissue samples, compared with the adjacent tissues [37.1\% (26/70) vs. $10 \%(2 / 20) ; \chi^{2}=5.374 ; \mathrm{P}=0.021$; Table II).

Association of PD-L1 methylation levels with clinical characteristics. PD-L1 methylation was significantly associated with lymph node staging (Table III): In the gastric cancer tissue group, a high methylation rate of the PD-L1 promoter region was significantly associated with the $\mathrm{N} 3$ stage, but not with patients from the N0-N2 group $(\mathrm{P}=0.049)$. However, no association was observed between PD-L1 methylation and the other clinical characteristics investigated.

PD-L1 promoter methylation is associated with increased protein expression. Of the 26 advanced gastric cancer tissues that were identified as positive for PD-L1 promoter methylation, 73.1\% were also positive for PD-L1 protein expression (Fig. 2). Additionally, out of the 44 cancer tissues negative for PD-L1 promoter methylation, $47.7 \%$ were positive for PD-L1 protein expression (Fig. 2). Furthermore, a significantly positive association between PD-L1 promoter methylation and protein expression was identified ( $\mathrm{P}=0.038$; Table IV).

Increased PD-L1 methylation predicts poor chemotherapeutic efficacy. In the population analyzed, chemotherapy was significantly more effective in patients with a non-methylated PD-L1 gene promoter $(\mathrm{P}=0.037)$ and lower lymph node stage $(\mathrm{P}=0.009)$. The rate of chemotherapeutic efficacy $(\mathrm{P}=0.038)$ and disease control $(\mathrm{P}=0.024)$ in patients with recurrence following radical gastrectomy was higher than that of patients who underwent palliative surgery. Consequently, these factors can be considered as predictors of chemotherapeutic efficacy in patients with gastric cancer. Other clinicopathological 
A

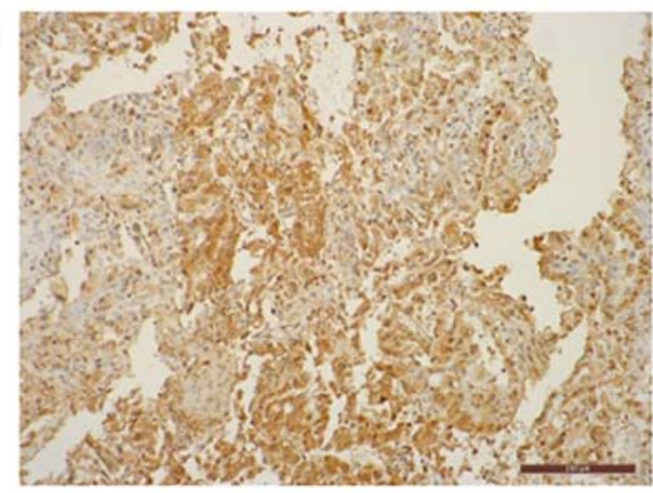

C

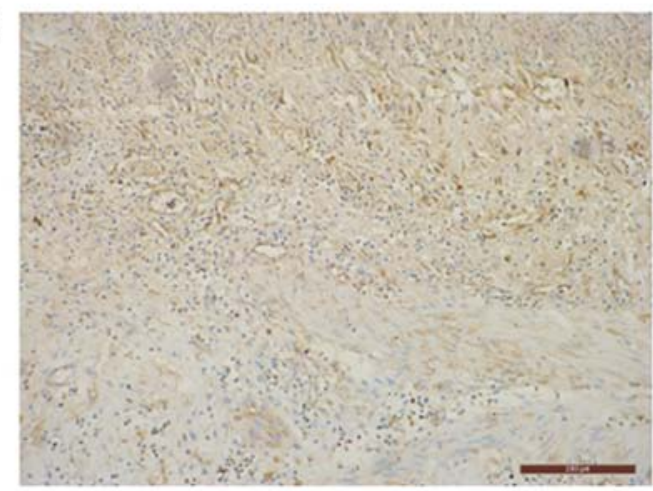

B



$\mathrm{D}$

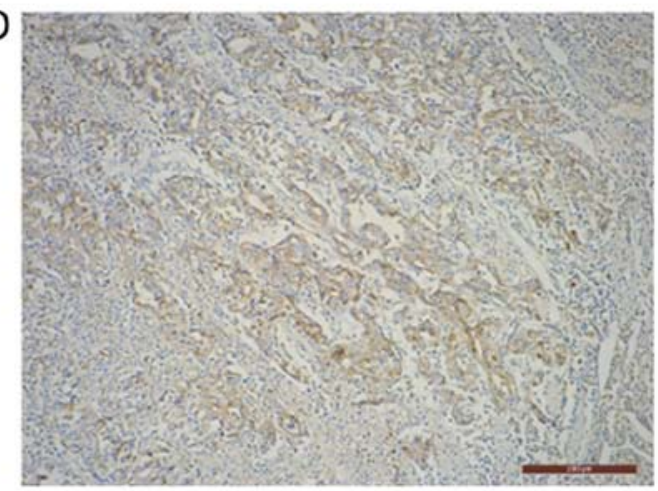

Figure 2. Tissue sections collected from patients with gastric cancer were stained for PD-L1. The intensity of extracellular staining of the PD-L1 promoter as observed in: (A) +++ methylated gastric cancer tissues; (B) ++, non-methylated gastric cancer tissues; (C) +, methylated gastric cancer tissues; and (D) +, non-methylated gastric cancer tissues. (magnification, $\mathrm{x} 400$ ). PD-L1, programmed cell death-Ligand 1.

Table II. Methylation status of PD-L1 in 70 gastric cancer and adjacent tissues.

\begin{tabular}{lrrrr}
\hline & \multicolumn{1}{c}{$\begin{array}{c}\text { PD-L1 promoter } \\
\text { methylation }\end{array}$} & & \\
\cline { 2 - 3 } Tissue type & Yes & No & P-value & $\chi^{2}$ value \\
\hline Gastric cancer & 26 & 44 & $0.021^{\mathrm{a}}$ & 5.374 \\
Adjacent tissues & 2 & 18 & & \\
\hline
\end{tabular}

PD-L1, programmed cell death-Ligand $1 .{ }^{\mathrm{a}} \mathrm{P}<0.05$.

characteristics and protein expression levels were not found to be significantly associated with chemotherapeutic efficacy (Table V).

The results of the multivariate logistic regression analysis are exhibited in Table VI. Certain pre-selected patient characteristics (number of lymph node metastases, recurrence after radical gastrectomy or palliative surgery, monotherapy or multi-drug combination therapy) and the degree of methylation were independent variables, and the effective rate of chemotherapy and disease control rate of patients were selected as the dependent variables. Multivariate logistic regression analysis demonstrated that PD-L1 methylation was able to independently predict chemotherapeutic efficacy in patients with gastric cancer. Patients with recurrence after radical gastrectomy exhibit improved chemotherapeutic effi- cacy and disease control rate compared with palliative surgery patients (Table VI).

PFS and OS analysis. Patients exhibiting positive PD-L1 methylation had lower mPFS and mOS times (log-rank test, Table VII) compared with patients with negative PD-L1 methylation; however, the difference between groups was not statistically significant (Fig. 3A and B). The association between survival time and PD-L1 protein expression was also not statistically significant (Table VII). Patients receiving platinum/fluorouracil chemotherapy had a longer mPFS, suggesting an overall improvement in PFS time in patients receiving this treatment type. A Cox proportional hazards regression model was constructed, in which multivariate survival analyses were applied to assess the association between mPFS and several clinical characteristics; however, no significant associations were determined. The mOS time was greater in patients with moderately- or well-differentiated tumors, compared with that in those with poorly-differentiated tumors $(\mathrm{P}=0.012$; log-rank test; Fig. 4$)$.

Prognostic significance of PD-L1 methylation and clinical characteristics. In the Cox proportional hazards regression model, univariate and multivariate survival analyses were performed to assess the association between PD-L1 methylation and several clinical characteristics. Univariate analyses demonstrated that tumor differentiation was associated with mOS time only. Multivariate analysis revealed that the degree of tumor differentiation $(\mathrm{P}=0.012$; $\mathrm{HR}=1.965)$ was able to independently predict patient prognosis (Table VIII). 
Table III. Correlation between PD-L1 promoter methylation and the clinicopathological characteristics.

\begin{tabular}{|c|c|c|c|c|}
\hline \multirow[b]{3}{*}{ Characteristic } & \multicolumn{3}{|c|}{ PD-L1 promoter methylation } & \multirow[b]{3}{*}{ P-value } \\
\hline & \multirow[b]{2}{*}{ Patients, n } & \multicolumn{2}{|c|}{ Methylation } & \\
\hline & & Yes & No & \\
\hline \multicolumn{5}{|l|}{ Sex } \\
\hline Male & 49 & 18 & 31 & 0.914 \\
\hline Female & 21 & 8 & 13 & \\
\hline \multicolumn{5}{|l|}{ Age, years } \\
\hline$\leq 60$ & 31 & 12 & 19 & 0.809 \\
\hline$>60$ & 39 & 14 & 25 & \\
\hline \multicolumn{5}{|c|}{ Recurrence/Palliative surgery } \\
\hline Recurrence & 32 & 12 & 20 & 0.955 \\
\hline Palliative surgery & 38 & 14 & 24 & \\
\hline \multicolumn{5}{|l|}{ Tumor size } \\
\hline$>5 \mathrm{~cm}$ & 32 & 10 & 22 & 0.326 \\
\hline$\leq 5 \mathrm{~cm}$ & 35 & 15 & 20 & \\
\hline \multicolumn{5}{|l|}{ Lymph node staging } \\
\hline $\mathrm{N} 0-\mathrm{N} 2$ & 34 & 9 & 25 & $0.049^{\mathrm{a}}$ \\
\hline N3 & 32 & 16 & 16 & \\
\hline \multicolumn{5}{|l|}{ Vessel carcinoma embolus } \\
\hline Positive & 35 & 14 & 21 & 0.653 \\
\hline Negative & 2 & 1 & 1 & \\
\hline \multicolumn{5}{|l|}{ Perineural invasion } \\
\hline Positive & 15 & 5 & 10 & 0.347 \\
\hline Negative & 5 & 3 & 2 & \\
\hline \multicolumn{5}{|l|}{ Degree of differentiation } \\
\hline Moderate or well & 32 & 10 & 22 & 0.326 \\
\hline Poor & 35 & 15 & 20 & \\
\hline \multicolumn{5}{|l|}{ Pathological type } \\
\hline Simple adenocarcinoma & 40 & 16 & 24 & 0.641 \\
\hline Other & 29 & 10 & 19 & \\
\hline
\end{tabular}

PD-L1, programmed cell death-Ligand $1 .{ }^{\mathrm{a}} \mathrm{P}<0.05$.

Of the 26 patients exhibiting a methylated PD-L1 promoter region, those receiving platinum/fluorouracil combination therapy had an mPFS 4.2 months longer than patients who received paclitaxel/fluorouracil chemotherapy $(\mathrm{P}=0.008$; log-rank test; Fig. 5; Table IX). Multivariate analysis included age and chemotherapy regimen as independent variables, but the model constructed indicated that age did not produce a significant result, and it contained only chemotherapy regimen variables. The risk of disease progression in patients receiving paclitaxel/fluorouracil chemotherapy was 5.009 times higher than in those who had received platinum/fluorouracil chemotherapy. Therefore, Platinum-containing first-line chemotherapy could represent an independent prognostic factor for PFS time in patients with advanced gastric cancer exhibiting methylated PD-L1 promoter regions $(\mathrm{P}=0.015$; Table $\mathrm{X})$. In the 44 patients with a non-methylated PD-L1 promoter region, patients with moder- ately- or well-differentiated tumors exhibited higher mPFS and mOS times than patients with poorly-differentiated tumors $(\mathrm{P}<0.05$; Table $\mathrm{SI})$ and there was no other statistically significant difference in survival time associated with with treatment regimen (Table SI).

\section{Discussion}

Numerous studies have suggested that the development of gastric cancer is a complex, multi-factorial and multi-signal biological process. Factors resulting in gene mutation and epigenetic modifications also serve an important role in the tumorigenesis and progression of gastric cancer (15). In multiple malignancies, aberrant DNA methylation patterns are associated with transcriptional repression, cell cycle disorder, abnormal activation or inactivation of signaling pathways, increased cell invasion, abnormal apoptotic mechanisms, 
Table IV. Association between PD-L1 promoter methylation and protein expression in advanced gastric cancer tissues.

\begin{tabular}{|c|c|c|c|c|c|}
\hline \multirow[b]{2}{*}{ PD-L1 promoter methylation } & \multicolumn{2}{|c|}{$\begin{array}{l}\text { PD-L1 protein } \\
\text { expression }\end{array}$} & \multirow[b]{2}{*}{ Total } & \multirow[b]{2}{*}{ P-value } & \multirow[b]{2}{*}{$\chi^{2}$ value } \\
\hline & + & - & & & \\
\hline Methylation & 19 & 7 & 26 & $0.038^{\mathrm{a}}$ & 4.288 \\
\hline No methylation & 21 & 23 & 44 & & \\
\hline Total & 40 & 30 & 70 & & \\
\hline
\end{tabular}

PD-L1, programmed cell death-Ligand $1 .{ }^{\mathrm{a}} \mathrm{P}<0.05$.

activation of proto-oncogenes and the promotion of tumorigenesis (16).

PD-L1 (also known as CD274 or B7-H1) is a type I glycoprotein expressed in various cells, including $\mathrm{T}$ cells, epithelial and endothelial cells, following the stimulation of proinflammatory mediators such as interferon- $\gamma(17)$. Various studies have demonstrated that PD-L1 is differentially expressed in solid tumors, and that it serves an important role in the development of numerous tumor types, including NSCLC (18), colon (19), breast (20) and ovarian cancers (21), and also in melanoma (22). A high expression level of PD-L1 is frequently observed in tumor cells and is associated with the promotion of metastasis and infiltration; it also facilitates tumor cell escape from $\mathrm{CD}^{+} \mathrm{T}$ cells, thereby allowing them to evade immune surveillance (23).

At present, the association between the expression level of PD-L1 and disease prognosis in patients with gastric cancer is inconclusive. Multiple studies have shown that the expression of PD-L1 is upregulated in gastric cancer tissues compared with little to no protein expression in adjacent tissues (24-26). Therefore, in the present study, IHC was performed to identify the different methylation states of the PD-L1 gene in gastric cancer tissues. Previous studies have illustrated that PD-L1 protein expression in gastric cancer is associated with tumor size, lymph node metastasis and the depth of tumor invasion. Moreover, patients with higher PD-L1 expression levels exhibited a short OS period, indicating that PD-L1 expression is an important prognostic factor in gastric cancer (24-26). However, a study in South Korea (27) determined that high expression levels of PD-L1 in gastric cancer cells predict favorable clinicopathological features and prognosis. At present, the majority of research on the PD-L1 gene in gastric cancer is focused on protein and mRNA expression, and not on methylation patterns. Therefore, in an attempt to elucidate its potential for the prediction of disease prognosis, the present study was conducted to explore the influence of PD-L1 gene methylation and protein expression in patients with advanced gastric cancer, and to characterize its association with various clinicopathological characteristics.

HMSP was used to detect the extent of PD-L1 methylation in gastric cancer tissues (37.1\%) compared with adjacent tissues $(10 \%)$. Previously, studies have concluded that methylation of the PD-L1 promoter in prostate cancer tissues is higher than in normal prostate tissue (28), corroborating the conclusions of the present study. Notably, certain studies have elucidated that in human melanoma, PD-L1 expression may be altered by DNA hypomethylating agents (29). Moreover, the expression level of PD-L1 can be regulated using DNA methylation, in response to NF- $\mathrm{\kappa B}$ or transforming growth factor- $\beta$ signaling in NSCLC (30). In the current study, the PD-L1 methylation status correlated with PD-L1 protein expression and the number of lymph node metastases, implying that methylation of the PD-L1 promoter may affect tumor progression in advanced gastric cancer tissues, via the regulation of protein expression. The results of the present study support the hypothesis that methylation of the PD-L1 promoter promotes lymph node metastasis, and that this may be due to changes in the tumor microenvironment resulting from PD-L1 hypermethylation. Further studies investigating the mechanism behind this process may offer insights into potential therapeutic targets or prognostic biomarkers. In summary, PD-L1 methylation regulates PD-L1 expression and may therefore, represent an optimal biomarker for the indication of tumor progression in patients with advanced gastric cancer.

It has previously been demonstrated that methylation of the PD-L1 promoter may influence prognosis in numerous cancer types. For example, increased methylation of PD-L1 was significantly associated with shorter recurrence-free survival and OS times in patients with colorectal cancer (31). Similarly, in prostate cancer, high levels of PD-L1 methylation correlated with an increased risk of recurrence (28). Micevic et al (29) demonstrated that in melanoma, PD-L1 hypermethylation was associated with poor OS, and was also considered an independent prognostic factor. By contrast, increased PD-L1 methylation was significantly associated with the reduced risk of relapse and prolonged OS times in patients with acute myelocytic leukemia (32). In the present study, chemotherapy was less effective in patients with methylated PD-L1 compared with those with no methylation (11.5 vs. $34.1 \%$; $n=70)$. The results also indicated that methylation of the PD-L1 promoter may represent an independent prognostic factor for chemotherapeutic efficacy in the treatment of advanced gastric cancer. Furthermore, patients with methylated PD-L1 promoters exhibited a shorter PFS and OS times than those without. The results of the current study also indicated a correlation between the methylation status of PD-L1 in the promoter region and OS time; however this result was not statistical significant, which may be due to the insufficient population size. Thus in the future, 
Table V. Correlation between clinicopathological characteristics and chemotherapeutic efficacy.

\begin{tabular}{|c|c|c|c|c|c|c|c|}
\hline \multirow[b]{2}{*}{ Characteristic } & \multirow[b]{2}{*}{ Patients, $\mathrm{n}$} & \multicolumn{2}{|c|}{ Chemotherapy effective } & \multirow[b]{2}{*}{ P-value } & \multicolumn{2}{|c|}{ Disease control } & \multirow[b]{2}{*}{ P-value } \\
\hline & & $\mathrm{SD}+\mathrm{PD}(\%)$ & $\mathrm{CR}+\mathrm{PR}(\%)$ & & $\mathrm{PD}(\%)$ & $\mathrm{CR}+\mathrm{PR}+\mathrm{SD}(\%)$ & \\
\hline Total, $\mathrm{n}$ & 70 & $52(74.3)$ & $18(25.7)$ & & $15(21.4)$ & $55(78.6)$ & \\
\hline \multicolumn{8}{|l|}{ Sex } \\
\hline Male & 49 & $35(71.4)$ & $14(28.6)$ & \multirow[t]{2}{*}{0.403} & $10(20.4)$ & $39(79.6)$ & \multirow[t]{2}{*}{0.990} \\
\hline Female & 21 & $17(81.0)$ & $4(19.0)$ & & $5(23.8)$ & $16(76.2)$ & \\
\hline \multicolumn{8}{|l|}{ Age, years } \\
\hline$\leq 60$ & 31 & $24(77.4)$ & $7(22.6)$ & \multirow[t]{2}{*}{0.593} & $6(19.3)$ & $25(80.7)$ & \multirow[t]{2}{*}{0.706} \\
\hline$>60$ & 39 & $28(71.8)$ & $11(28.2)$ & & $9(23.1)$ & $30(76.9)$ & \\
\hline \multicolumn{8}{|c|}{ PD-L1 promoter methylation } \\
\hline Methylation & 26 & $23(88.5)$ & $3(11.5)$ & \multirow[t]{2}{*}{$0.037^{\mathrm{a}}$} & $6(23.1)$ & $20(76.9)$ & \multirow[t]{2}{*}{0.796} \\
\hline No methylation & 44 & $29(65.9)$ & $15(34.1)$ & & $9(20.5)$ & $35(79.5)$ & \\
\hline \multicolumn{8}{|c|}{ Recurrence/Palliative surgery } \\
\hline Recurrence & 32 & $20(62.5)$ & $12(37.5)$ & \multirow[t]{2}{*}{$0.038^{\mathrm{a}}$} & $3(9.4)$ & $29(90.6)$ & \multirow[t]{2}{*}{$0.024^{\mathrm{a}}$} \\
\hline Palliative surgery & 38 & $32(84.2)$ & $6(15.8)$ & & $12(31.6)$ & $26(68.4)$ & \\
\hline \multicolumn{8}{|l|}{ Lymph node stage } \\
\hline N0-N2 & 34 & $20(58.8)$ & $14(41.2)$ & \multirow[t]{2}{*}{$0.009^{\mathrm{a}}$} & $5(14.7)$ & $29(85.3)$ & \multirow[t]{2}{*}{0.293} \\
\hline N3 & 32 & $28(87.5)$ & $4(12.5)$ & & $8(25.0)$ & $24(75.0)$ & \\
\hline \multicolumn{8}{|l|}{ Vessel carcinoma embolus } \\
\hline Positive & 35 & $27(77.1)$ & $8(22.9)$ & \multirow[t]{2}{*}{0.432} & $7(20.0)$ & $8(80.0)$ & \multirow[t]{2}{*}{0.990} \\
\hline Negative & 2 & $1(50.0)$ & $1(50.0)$ & & $0(0)$ & $2(100)$ & \\
\hline Perineural invasion & & & & & & & \\
\hline Positive & 15 & $10(66.6)$ & $5(33.3)$ & 0.990 & $1(6.7)$ & $14(93.3)$ & 0.140 \\
\hline Negative & 5 & $4(80)$ & $1(20)$ & & $2(40)$ & $3(60)$ & \\
\hline Degree of differentiation & & & & & & & \\
\hline Moderate or well & 32 & $22(68.8)$ & $10(31.2)$ & 0.290 & $4(12.5)$ & $28(87.5)$ & 0.063 \\
\hline Poor & 35 & $28(80.0)$ & $7(20.0)$ & & $11(31.4)$ & $24(68.6)$ & \\
\hline Pathological type & & & & & & & \\
\hline Simple adenocarcinoma & 40 & $31(77.5)$ & $9(22.5)$ & 0.426 & $10(25.0)$ & $30(75.0)$ & 0.441 \\
\hline Other & 29 & $20(69.0)$ & $9(31.0)$ & & $5(17.2)$ & $24(82.8)$ & \\
\hline Tumor size & & & & & & & \\
\hline$>5 \mathrm{~cm}$ & 32 & $25(78.1)$ & $7(21.9)$ & 0.378 & $6(18.75)$ & $26(81.25)$ & 0.680 \\
\hline$\leq 5 \mathrm{~cm}$ & 35 & $24(68.6)$ & $11(31.4)$ & & $8(22.9)$ & $27(77.1)$ & \\
\hline Therapy & & & & & & & \\
\hline Multi-drug combination & 58 & $40(69.0)$ & $18(31.0)$ & 0.061 & $10(17.2)$ & $48(82.8)$ & 0.136 \\
\hline Monotherapy & 12 & $12(100)$ & $0(0)$ & & $5(41.7)$ & $7(58.3)$ & \\
\hline Chemotherapy regimen & & & & & & & \\
\hline Paclitaxel/Fluorouracil & 24 & $17(70.8)$ & $7(29.2)$ & 0.749 & $6(25.0)$ & $18(75.0)$ & 0.181 \\
\hline Platinum/Fluorouracil & 27 & $18(66.7)$ & $9(33.3)$ & & $2(7.4)$ & $25(92.6)$ & \\
\hline PD-L1 protein expression & & & & & & & \\
\hline+ & 40 & $30(70.8)$ & $10(55.6)$ & 0.875 & $7(46.7)$ & $33(60.0)$ & 0.355 \\
\hline- & 30 & $22(66.7)$ & $8(44.4)$ & & $8(53.3)$ & $22(40.0)$ & \\
\hline
\end{tabular}

PD-L1, programmed cell death-Ligand 1; CR, complete response; PR, partial response; SD, stable disease; PD, progressive disease. ${ }^{\text {P }}<0.05$

further studies should be conducted on larger populations to increase the validity of the conclusions drawn.

In the present study, the log-rank test was used to compare the OS times, and to determine the association between,
PD-L1 protein expression and prognosis. However, in contrast to previous studies, a significant association between PD-L1 expression and prognosis was not determined, perhaps due to the fact that protein expression is not solely regulated by DNA 
Table VI. Multivariate logistic regression analysis.

\begin{tabular}{|c|c|c|c|c|c|c|}
\hline \multirow[b]{2}{*}{ Characteristic } & \multicolumn{3}{|c|}{ Chemotherapy effective } & \multicolumn{3}{|c|}{ Disease control } \\
\hline & OR & $95 \%$ CI & P-value & OR & $95 \% \mathrm{CI}$ & P-value \\
\hline PD-L1 promoter methylation & 6.784 & $1.383-33.280$ & $0.018^{\mathrm{a}}$ & & & \\
\hline Recurrence/palliative surgery & 4.252 & $1.036-17.456$ & $0.045^{\mathrm{a}}$ & 6.350 & $1.377-29.274$ & $0.018^{\mathrm{a}}$ \\
\hline Lymph node staging & 0.235 & $0.057-0.965$ & 0.082 & 5.588 & $1.175-26.568$ & $0.031^{\mathrm{a}}$ \\
\hline Monotherapy/multi-drug combination & - & 0.000 & 0.998 & & & \\
\hline
\end{tabular}

${ }^{\mathrm{a}} \mathrm{P}<0.05$. PD-L1, Programmed cell death-Ligand 1; OR, odds ratio; CI, confidence interval.
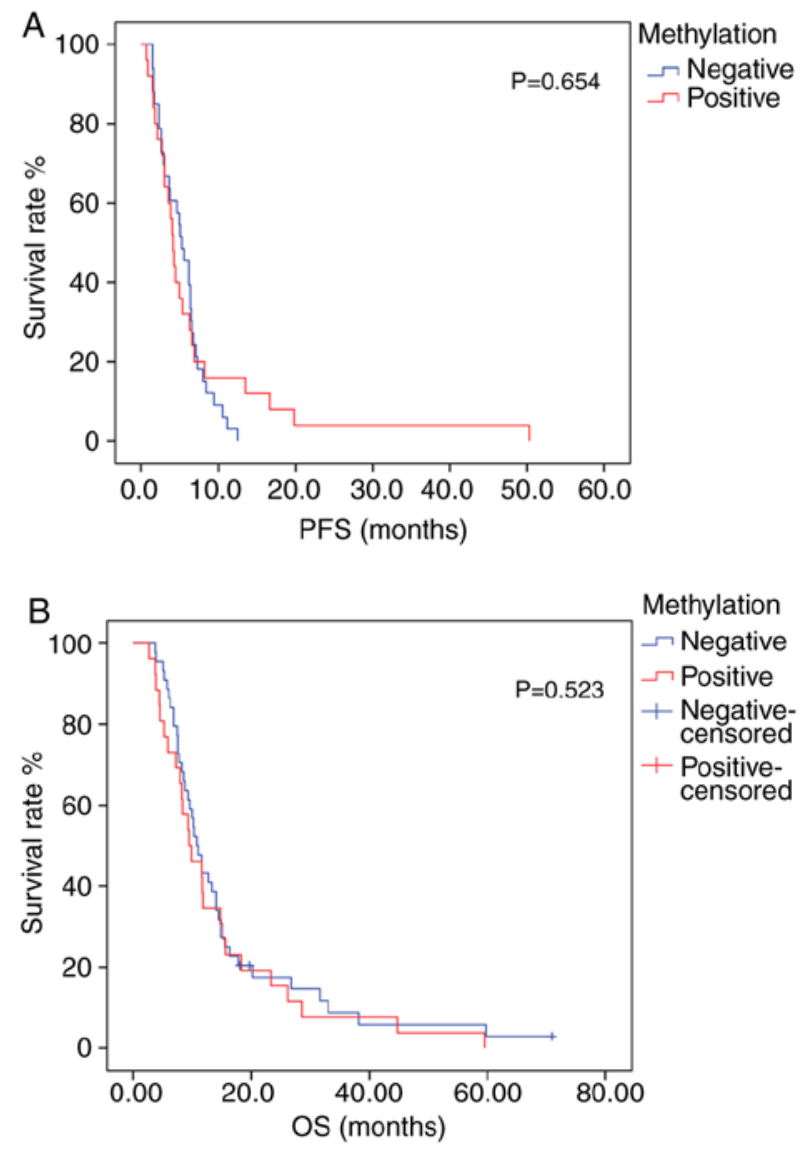

Figure 3. Kaplan-Meier survival plot of (A) PFS and (B) OS time based on the methylation status of PD-L1. PFS, progression-free survival; OS, overall survival; PD-L1, programmed cell death-Ligand 1.

methylation, but also by other upstream factors. Other potential explanations for this inconsistency may be differences in sample size, methods of tissue preservation (fresh frozen tissue vs. paraffin-embedded tissue), detection platforms and antibodies used, and different thresholds selected.

The current study demonstrated that PD-L1 methylation is positively correlated with PD-L1 protein expression, indicating that PD-L1 expression may be regulated by promoter methylation in gastric cancer. Previous research has reported that PD-L1 methylation is inversely correlated with PD-L1 mRNA expression (31). Perhaps, PD-L1 methylation regulates protein expression at the mRNA level. A lack of data regarding

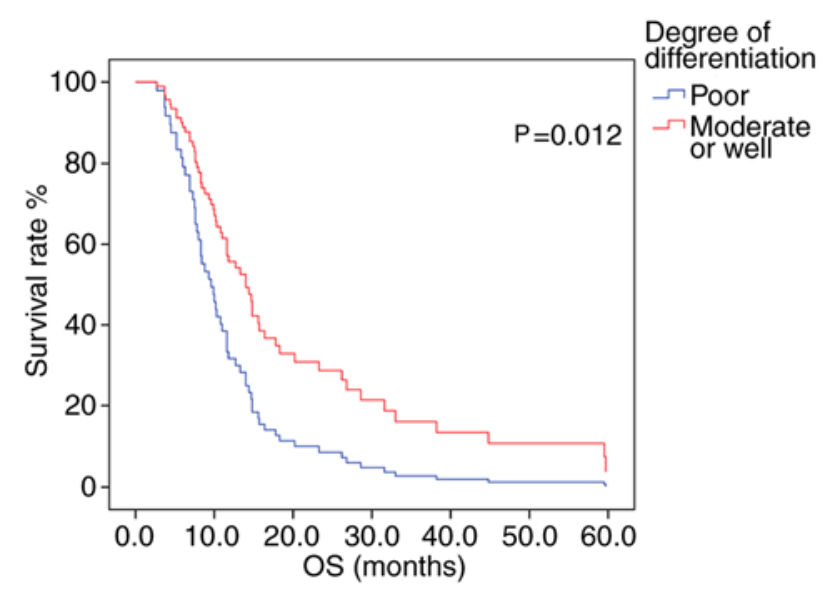

Figure 4. Kaplan-Meier survival plot of OS time based on degree of differentiation (moderate and well/poor). OS, overall survival.

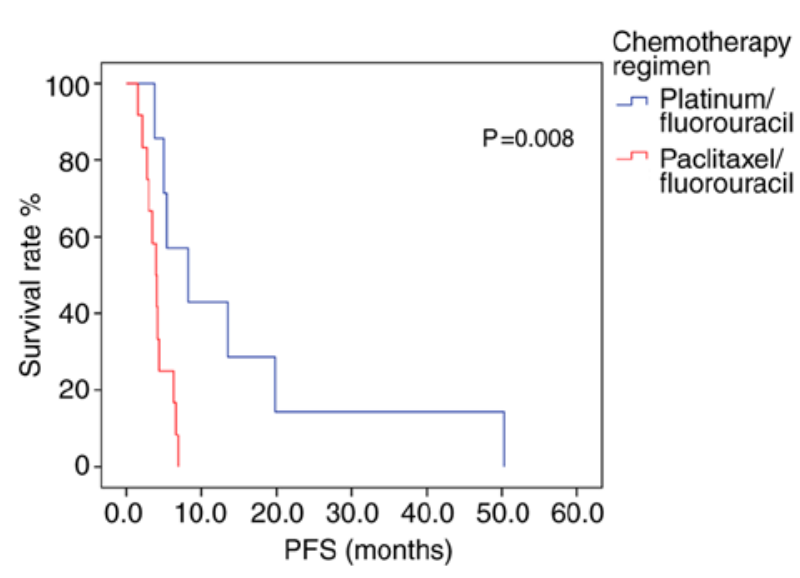

Figure 5. Kaplan-Meier survival plot of PFS based on chemotherapy regimen in patients with a methylated PD-L1 promoter region. PFS, progression-free survival; PD-L1, programmed cell death-Ligand 1.

PD-L1 mRNA expression meant that this was a limitation of the present study, thus future research should investigate the associations between PD-L1 promoter methylation, mRNA and protein expression in gastric cancer.

At present, first-line chemotherapy for advanced gastric cancer consists of fluorouracil, which is typically combined with platinum and/or paclitaxel to form a two- or three-drug 
Table VII. Survival outcome of 70 gastric patients.

\begin{tabular}{|c|c|c|c|c|c|c|c|c|}
\hline \multirow[b]{2}{*}{ Characteristic } & \multicolumn{3}{|c|}{ PFS } & \multirow[b]{2}{*}{$\begin{array}{c}\text { Patients, } \\
n\end{array}$} & \multicolumn{3}{|c|}{ OS, months } & \multirow[b]{2}{*}{$\begin{array}{c}\text { Patients, } \\
\text { n }\end{array}$} \\
\hline & $\begin{array}{l}\text { mPFS, } \\
\text { months }\end{array}$ & $\chi^{2}$ value & P-value & & $\begin{array}{l}\text { mOS, } \\
\text { months }\end{array}$ & $\chi^{2}$ value & P-value & \\
\hline \multicolumn{9}{|l|}{ Sex } \\
\hline Male & 5.0 & 0.240 & 0.624 & 42 & 10.3 & 0.083 & 0.773 & 47 \\
\hline Female & 4.2 & & & 16 & 11.0 & & & 20 \\
\hline \multicolumn{9}{|l|}{ Age, years } \\
\hline$\leq 60$ & 5.6 & 3.630 & 0.057 & 27 & 10.2 & 0.011 & 0.916 & 29 \\
\hline$>60$ & 4.4 & & & 31 & 11.0 & & & 38 \\
\hline \multicolumn{9}{|c|}{ PD-L1 promoter methylation } \\
\hline Methylation & 4.1 & 0.201 & 0.654 & 25 & 9.5 & 0.409 & 0.523 & 26 \\
\hline No methylation & 5.3 & & & 33 & 10.8 & & & 41 \\
\hline \multicolumn{9}{|l|}{ Chemotherapy regimen } \\
\hline Platinum/Fluorouracil & 5.6 & 3.869 & $0.049^{\mathrm{a}}$ & 19 & 11.6 & 0.997 & 0.318 & 26 \\
\hline Paclitaxel/Fluorouracil & 4.2 & & & 23 & 10.3 & & & 24 \\
\hline \multicolumn{9}{|c|}{ Recurrence/Palliative surgery } \\
\hline Recurrence & 5 & 1.455 & 0.228 & 25 & 11.6 & 3.141 & 0.076 & 30 \\
\hline Palliative operation & 3.8 & & & 33 & 9.5 & & & 37 \\
\hline \multicolumn{9}{|l|}{ Degree of differentiation } \\
\hline Moderate or well & 5.1 & 0.237 & 0.626 & 23 & 14.0 & 7.574 & $0.006^{\mathrm{a}}$ & 29 \\
\hline Poor & 3.8 & & & 32 & 8.4 & & & 35 \\
\hline \multicolumn{9}{|l|}{ Pathological type } \\
\hline Simple adenocarcinoma & 4.0 & 0.959 & 0.328 & 31 & 11.6 & 0.801 & 0.371 & 39 \\
\hline Other & 5.3 & & & 26 & 8.8 & & & 27 \\
\hline \multicolumn{9}{|l|}{ Tumor size } \\
\hline$>5 \mathrm{~cm}$ & 5.0 & 0.348 & 0.555 & 26 & 10.0 & 1.834 & 0.176 & 31 \\
\hline$\leq 5 \mathrm{~cm}$ & 4.4 & & & 29 & 10.8 & & & 33 \\
\hline \multicolumn{9}{|l|}{ Lymph node staging } \\
\hline N0-N2 & 5.0 & 0.064 & 0.801 & 25 & 11.6 & 2.602 & 0.107 & 32 \\
\hline N3 & 5.4 & & & 29 & 9.9 & & & 31 \\
\hline \multicolumn{9}{|l|}{ PD-L1 protein expression } \\
\hline+ & 5.6 & 2.480 & 0.115 & 35 & 11.6 & 0.461 & 0.479 & 40 \\
\hline- & 3.7 & & & 23 & 8.6 & & & 30 \\
\hline
\end{tabular}

${ }^{\text {a }}$ < 0.05. PD-L1, programmed cell death-ligand 1; PFS, progression-free survival; OS, overall survival.

regimen (33). Since there were fewer patients in the single-agent and three-drug combination chemotherapy groups, the patients with double-drug combination chemotherapy were further analyzed. According to the chemotherapy regimen, patients were divided into paclitaxel/fluorouracil or platinum/fluorouracil chemotherapy groups and it was discovered that the PFS time of the patients receiving a first-line chemotherapy regimen of platinum combined with fluorouracil was 5.6 months, which was longer than that of the patients receiving paclitaxel combined with fluorouracil (4.2 months). Therefore, platinum/fluorouracil combination treatment confers a longer PFS time than paclitaxel/fluorouracil, in patients with advanced gastric cancer.

Further investigation of the association between PD-L1 promoter methylation and first-line chemotherapeutic efficacy for advanced gastric cancer revealed that, in 26 patients exhibiting methylated PD-L1, the mPFS time (8.2 months) of patients receiving platinum/fluorouracil chemotherapy was significantly longer than in patients receiving paclitaxel/fluorouracil (4.0 months). Furthermore, the risk of disease progression in patients treated with paclitaxel/fluorouracil chemotherapy was 5.009 times higher compared with patients receiving platinum/fluorouracil chemotherapy. Recent research has determined that the breast cancer 1 , early onset gene expression level is correlated with the treatment response to cisplatin and oxaliplatin in patients with gastric cancer (34). Phosphatase and tensin homolog gene deficiency was observed in BRCA1 mutation cancers $(35,36)$. Loss of PTEN has been shown to increase PD-L1 expression via the PI3K pathway $(37,38)$. In 
Table VIII. Cox proportional hazards assessment of prognostic factors in 70 gastric cancer patients.

\begin{tabular}{lccccccc}
\hline Factor & & & & & \multicolumn{2}{c}{$95 \%$ CI } \\
\hline Degree of differentiation & 0.675 & 0.270 & 6.255 & 0.012 & 1.965 & 1.157 & 3.336 \\
\hline
\end{tabular}

HR, hazard ratio; SE, standard error; CI, confidence interval.

Table IX. Survival outcome of 26 patients exhibiting methylated PD-L1.

\begin{tabular}{|c|c|c|c|c|c|c|c|c|}
\hline \multirow[b]{2}{*}{ Characteristic } & \multicolumn{3}{|c|}{ PFS } & \multirow[b]{2}{*}{$\begin{array}{c}\text { Patients, } \\
n\end{array}$} & \multicolumn{3}{|c|}{ OS } & \multirow[b]{2}{*}{$\begin{array}{c}\text { Patients } \\
\mathrm{n}\end{array}$} \\
\hline & $\begin{array}{l}\text { mPFS, } \\
\text { months }\end{array}$ & $\chi^{2}$ value & P-value & & $\begin{array}{l}\text { mOS, } \\
\text { months }\end{array}$ & $\chi^{2}$ value & P-value & \\
\hline \multicolumn{9}{|l|}{ Sex } \\
\hline Male & 3.8 & 0.335 & 0.563 & 18 & 11.6 & 0.005 & 0.946 & 18 \\
\hline Female & 4.2 & & & 7 & 8.4 & & & 8 \\
\hline \multicolumn{9}{|l|}{ Age (years) } \\
\hline$\leq 60$ & 6.3 & 6.132 & $0.013^{\mathrm{a}}$ & 12 & 9.5 & 2.825 & 0.093 & 12 \\
\hline$>60$ & 4.0 & & & 13 & 9.3 & & & 14 \\
\hline \multicolumn{9}{|l|}{ Chemotherapy regimen } \\
\hline Platinum/Fluorouracil & 8.2 & 7.115 & $0.008^{\mathrm{a}}$ & 7 & 11.7 & 2.994 & 0.084 & 8 \\
\hline Paclitaxel/Fluorouracil & 4.0 & & & 12 & 9.3 & & & 12 \\
\hline \multicolumn{9}{|c|}{ Recurrence/Palliative surgery } \\
\hline Recurrence & 4.2 & 1.926 & 0.165 & 11 & 11.6 & 3.474 & 0.062 & 12 \\
\hline Palliative surgery & 3.5 & & & 14 & 7.3 & & & 14 \\
\hline \multicolumn{9}{|l|}{ Degree of differentiation } \\
\hline Moderate or well & 3.5 & 1.434 & 0.231 & 9 & 9.3 & 0.206 & 0.65 & 10 \\
\hline Poor & 5.0 & & & 15 & 11.6 & & & 15 \\
\hline \multicolumn{9}{|l|}{ Pathological type } \\
\hline Simple adenocarcinoma & 3.5 & 2.790 & 0.095 & 15 & 9.5 & 0.353 & 0.553 & 16 \\
\hline Other & 5.4 & & & 10 & 8.3 & & & 10 \\
\hline \multicolumn{9}{|l|}{ Tumor size } \\
\hline$>5 \mathrm{~cm}$ & 3.8 & 0.223 & 0.637 & 10 & 9.5 & 0.081 & 0.776 & 10 \\
\hline$\leq 5 \mathrm{~cm}$ & 4.0 & & & 14 & 8.4 & & & 15 \\
\hline \multicolumn{9}{|l|}{ Lymph node staging } \\
\hline N0-N2 & 4.2 & 0.036 & 0.849 & 9 & 9.3 & 0.033 & 0.855 & 9 \\
\hline N3 & 4.0 & & & 15 & 9.9 & & & 16 \\
\hline
\end{tabular}

${ }^{\mathrm{a}} \mathrm{P}<0.05$; PD-L1, programmed cell death-ligand 1; PFS, progression-free survival; OS, overall survival.

Table X. Cox proportional hazard assessment of prognostic factors in 26 patients exhibiting methylated Programmed cell death-Ligand 1.

\begin{tabular}{lcccccccc}
\hline Variable & & & & & & & \multicolumn{2}{c}{$95 \%$ CI } \\
\cline { 3 - 9 } & B & SE & Wald & P-value & HR & Lower & Upper \\
\hline
\end{tabular}

HR, hazard ratio; SE, standard error; CI, confidence interval. ${ }^{a} \mathrm{P}<0.05$ vs. control. 
the current study, methylation status correlated with PD-L1 protein expression. It was hypothesized that patients exhibiting a methylated PD-L1 promoter region may also possess BRCA1 gene mutations, and would see the greatest degree of improvement from platinum-based chemotherapy, potentially resulting in longer PFS times. Thus, detecting the methylation status of the PD-L1 promoter region may offer guidance regarding clinical decision-making.

Enhancements in immunotherapy have greatly improved the prognosis of patients with numerous cancer types. The PD-1/PD-L1 axis is an inhibitory signaling pathway associated with T-cell inactivation and exhaustion, which prevents excessive inflammatory responses (39). Immune checkpoint inhibitors significantly enhance T-cell function and therefore exert antitumor activity (40). Results from the phase II KEYNOTE-059 study (41) indicated that the monoclonal anti-PD-1 antibody pembrolizumab provided an objective response rate of $60 \%$ in previously untreated advanced gastric/gastroesophageal junction adenocarcinoma. Pembrolizumab monotherapy showed improved efficacy and manageable safety in patients with advanced gastric or gastroesophageal cancer who had previously received $\geq 2$ lines of treatment (42). Further studies are needed to determine whether PD-L1 promoter methylation allows for survival prediction in patients with advanced gastric cancer treated with PD-1/PD-L1 antagonists.

In summary, the present study demonstrated that the frequency of PD-L1 methylation was higher in gastric cancer tissues compared with adjacent tissues, and that this correlated with both protein expression of PD-L1 and the number of lymph node metastases. This suggests that methylation frequency significantly influences chemotherapeutic efficacy, and hence, may inform clinical decisions regarding treatment. Therefore, the results of the present study support the conclusion that methylation of PD-L1 in the promoter region may represent an independent prognostic factor, affecting the efficacy of chemotherapy in advanced gastric cancer via the regulation of protein expression. It may therefore be used as a novel biomarker for the prediction of first-line chemotherapeutic efficacy and the prognosis of patients receiving platinum-containing chemotherapy regimens for the treatment of advanced gastric cancer.

\section{Acknowledgements}

Not applicable.

\section{Funding}

No funding was received.

\section{Availability of data and materials}

All data that were generated or analyzed in the present study are included in this manuscript.

\section{Authors' contributions}

DL, CX and TW conceived and designed the study. DL and LC acquired the data. DL, LC, YZ, TW and NG analyzed and interpreted the data. DL, TW and NG drafted the article. All authors critically revised the article for important intellectual content and approved the final version of the article to be published.

\section{Ethics approval and consent to participate}

The present study was approved by the Ethics Committee of the Second Affiliated Hospital of Dalian Medical University, and all patients provided written informed consent.

\section{Patient consent for publication}

Not applicable.

\section{Competing interests}

The authors declare that they have no competing interests.

\section{References}

1. Bray F, Ferlay J, Soerjomataram I, Siegel RL, Torre LA and Jemal A: Global cancer statistics 2018: GLOBOCAN estimates of incidence and mortality worldwide for 36 cancers in 185 countries. CA Cancer J Clin 68: 394-424, 2018.

2. Meyer HJ and Wilke H: Treatment strategies in gastric cancer. Dtsch Arztebl Int 108: 698-706, 2011.

3. Shitara K: Chemotherapy for advanced gastric cancer: Future perspective in Japan. Gastric Cancer 20 (Suppl 1): S102-S110, 2017.

4. Herman JG and Baylin SB: Gene silencing in cancer in association with promoter hypermethylation. N Engl J Med 349: 2042-2054, 2003.

5. Wilson AS, Power BE and Molloy PL: DNA hypomethylation and human diseases. Biochim Biophys Acta 1775: 138-162, 2007.

6. NandakumarV,VaidMandKatiyarSK:(-)-Epigallocatechin-3-gallate reactivates silenced tumor suppressor genes, Cip1/p21 and p16INK4a, by reducing DNA methylation and increasing histones acetylation in human skin cancer cells. Carcinogenesis 32: 537-544, 2011.

7. Farias N, Ho N, Butler S, Delaney L, Morrison J, Shahrzad S and Coomber BL: The effects of folic acid on global DNA methylation and colonosphere formation in colon cancer cell lines. J Nutr Biochem 26: 818-826, 2015.

8. Pan Y, Liu G, Zhou F, Su B and Li Y: DNA methylation profiles in cancer diagnosis and therapeutics. Clin Exp Med 18: 1-14, 2018.

9. Constantinidou A, Alifieris C and Trafalis DT: Targeting programmed cell death-1 (PD-1) and ligand (PD-L1): A new era in cancer active immunotherapy. Pharmacol Ther 194: 84-106, 2019.

10. Zhang J, Dang F, Ren J and Wei W: Biochemical aspects of PD-L1 regulation in cancer immunotherapy. Trends Biochem Sci 43: 1014-1032, 2018

11. Pilon-Thomas S, Mackay A, Vohra N and Mulé JJ: Blockade of programmed death ligand 1 enhances the therapeutic efficacy of combination immunotherapy against melanoma. J Immunol 184: 3442-3449, 2010

12. Rizvi NA, Hellmann MD, Brahmer JR, Juergens RA, Borghaei H, Gettinger S, Chow LQ, Gerber DE, Laurie SA, Goldman JW, et al: Nivolumab in combination with platinum-based doublet chemotherapy for first-line treatment of advanced non-small-cell lung cancer. J Clin Oncol 34: 2969-2979, 2016.

13. Wang $\mathrm{Y}$, Wu L, Tian $\mathrm{C}$ and Zhang $\mathrm{Y}$ : PD-1-PD-L1 immune-checkpoint blockade in malignant lymphomas. Ann Hematol 97: 229-237, 2018.

14. Fromowitz FB, Viola MV, Chao S, Oravez S, Mishriki Y, Finkel G, Grimson R and Lundy J: Ras p21 expression in the progression of breast cancer. Hum Pathol 18: 1268-1275, 1987.

15. Samadani AA, Noroollahi SE, Mansour-Ghanaei F, Rashidy-Pour A, Joukar F and Bandegi AR: Fluctuations of epigenetic regulations in human gastric Adenocarcinoma: How does it affect? Biomed Pharmacother 109: 144-156, 2019.

16. Li Y, Liang J and Hou P: Hypermethylation in gastric cancer. Clin Chim Acta 448: 124-132, 2015. 
17. Dong H, Strome SE, Salomao DR, Tamura H, Hirano F, Flies DB Roche PC, Lu J, Zhu G, Tamada K, et al: Tumor-associated B7-H1 promotes T-cell apoptosis: A potential mechanism of immune evasion. Nat Med 8: 793-800, 2002.

18. Passiglia F, Bronte G, Bazan V, Natoli C, Rizzo S, Galvano A, Listì A, Cicero G, Rolfo C, Santini D and Russo A: PD-L1 expression as predictive biomarker in patients with NSCLC: A pooled analysis. Oncotarget 7: 19738-19747, 2016.

19. Koganemaru S, Inoshita N, Miura Y, Miyama Y, Fukui Y, Ozaki Y, Tomizawa K, Hanaoka Y, Toda S, Suyama K, et al: Prognostic value of programmed death-ligand 1 expression in patients with stage III colorectal cancer. Cancer Sci 108: 853-858, 2017.

20. Wang C, Zhu H, Zhou Y, Mao F, Lin Y, Pan B, Zhang X, Xu Q, Huang X and Sun Q: Prognostic value of PD-L1 in breast cancer: A meta-analysis. Breast J 23: 436-443, 2017.

21. Drakes ML, Mehrotra S, Aldulescu M, Potkul RK, Liu Y, Grisoli A, Joyce C, O'Brien TE, Stack MS and Stiff PJ: Stratification of ovarian tumor pathology by expression of programmed cell death-1 (PD-1) and PD-ligand 1 (PD-L1) in ovarian cancer. J Ovarian Res 11: 43, 2018.

22. Hino R, Kabashima K, Kato Y, Yagi H, Nakamura M, Honjo T, Okazaki T and Tokura Y: Tumor cell expression of programmed cell death-1 ligand 1 is a prognostic factor for malignant melanoma. Cancer 116: 1757-1766, 2010.

23. Larsen SK: Cellular immune responses towards regulatory cells. Dan Med J 63: B5188, 2016.

24. Sun J, Xu K, Wu C, Wang Y, Hu Y, Zhu Y, Chen Y, Shi Q, Yu G and Zhang $\mathrm{X}$ : PD-L1 expression analysis in gastric carcinoma tissue and blocking of tumor-associated PD-L1 signaling by two functional monoclonal antibodies. Tissue Antigens 69: 19-27, 2007.

25. Jiang D, Xu YY, Li F, Xu B and Zhang XG: The role of B7-H1 in gastric carcinoma: Clinical significance and related mechanism. Med Oncol 31: 268, 2014.

26. Qing Y, Li Q, Ren T, Xia W, Peng Y, Liu GL, Luo H, Yang YX, Dai XY, Zhou SF and Wang D: Upregulation of PD-L1 and APE1 is associated with tumorigenesis and poor prognosis of gastric cancer. Drug Des Devel Ther 9: 901-909, 2015.

27. Kim JW, Nam KH, Ahn SH, Park DJ, Kim HH, Kim SH, Chang H, Lee JO, Kim YJ, Lee HS, et al: Prognostic implications of immunosuppressive protein expression in tumors as well as immune cell infiltration within the tumor microenvironment in gastric cancer. Gastric Cancer 19: 42-52, 2016.

28. Gevensleben H, Holmes EE, Goltz D, Dietrich J, Sailer V, Ellinger J, Dietrich D and Kristiansen G: PD-L1 promoter methylation is a prognostic biomarker for biochemical recurrence-free survival in prostate cancer patients following radical prostatectomy. Oncotarget 7: 79943-79955, 2016.

29. Micevic G, Thakral D, McGeary M and Bosenberg M: PD-L1 methylation regulates PD-L1 expression and is associated with melanoma survival. Pigment Cell Melanoma Res 32: 435-440, 2019.

30. Asgarova A, Asgarov K, Godet Y, Peixoto P, Nadaradjane A, Boyer-Guittaut M, Galaine J, Guenat D, Mougey V, Perrard J, et al PD-L1 expression is regulated by both DNA methylation and NF-kB during EMT signaling in non-small cell lung carcinoma. Oncoimmunology 7: e1423170, 2018.
31. Goltz D, Gevensleben H, Dietrich J and Dietrich D: PD-L1 (CD274) promoter methylation predicts survival in colorectal cancer patients. Oncoimmunology 6: e1257454, 2016.

32. Goltz D, Gevensleben H, Grünen S, Dietrich J, Kristiansen G, Landsberg J and Dietrich D: PD-L1 (CD274) promoter methylation predicts survival in patients with acute myeloid leukemia. Leukemia 31: 738-743, 2017.

33. Wang FH, Shen L, Li J, Zhou ZW, Liang H, Zhang XT, Tang L, Xin Y, Jin J, Zhang YJ, et al: The Chinese society of clinical oncology (CSCO): Clinical guidelines for the diagnosis and treatment of gastric cancer. Cancer Commun (Lond) 39: 10, 2019.

34. Kim G, Kim J, Han SY, Hwang IG, Kim HS and Min H: The effects of BRCA1 expression on the chemosensitivity of gastric cancer cells to platinum agents. Oncol Lett 17: 5023-5029, 2019.

35. Saal LH, Gruvberger-Saal SK, Persson C, Lövgren K, Jumppanen M, Staaf J, Jönsson G, Pires MM, Maurer M, Holm K, et al: Recurrent gross mutations of the PTEN tumor suppressor gene in breast cancers with deficient DSB repair. Nat Genet 40: 102-107, 2008.

36. Phuah SY, Looi LM, Hassan N, Rhodes A, Dean S, Taib NA, Yip $\mathrm{CH}$ and Teo SH: Triple-negative breast cancer and PTEN (phosphatase and tensin homologue) loss are predictors of BRCA1 germline mutations in women with early-onset and familial breast cancer, but not in women with isolated late-onset breast cancer. Breast Cancer Res 14: R142, 2012.

37. Mittendorf EA, Philips AV, Meric-Bernstam F, Qiao N, Wu Y, Harrington S, Su X, Wang Y, Gonzalez-Angulo AM, Akcakanat A, et al: PD-L1 expression in triple-negative breast cancer. Cancer Immunol Res 2: 361-370, 2014.

38. Song M, Chen D, Lu B, Wang C, Zhang J, Huang L, Wang X, Timmons CL, Hu J, Liu B, et al: PTEN loss increases PD-L1 protein expression and affects the correlation between PD-L1 expression and clinical parameters in colorectal cancer. PLoS One 8: e65821, 2013

39. Zhou Q, Munger ME, Highfill SL, Tolar J, Weigel BJ, Riddle M, Sharpe AH, Vallera DA, Azuma M, Levine BL, et al: Program death-1 signaling and regulatory $\mathrm{T}$ cells collaborate to resist the function of adoptively transferred cytotoxic $\mathrm{T}$ lymphocytes in advanced acute myeloid leukemia. Blood 116: 2484-2493, 2010.

40. Brahmer JR, Tykodi SS, Chow LQ, Hwu WJ, Topalian SL, Hwu P, Drake CG, Camacho LH, Kauh J, Odunsi K, et al: Safety and activity of anti-PD-L1 antibody in patients with advanced cancer. N Engl J Med 366: 2455-2465, 2012.

41. Bang YJ, Kang YK, Catenacci DV, Muro K, Fuchs CS, Geva R, Hara H, Golan T, Garrido M, Jalal SI, et al: Pembrolizumab alone or in combination with chemotherapy as first-line therapy for patients with advanced gastric or gastroesophageal junction adenocarcinoma: Results from the phase II nonrandomized KEYNOTE-059 study. Gastric Cancer 22: 828-837, 2019.

42. Fuchs CS, Doi T, Jang RW, Muro K, Satoh T, Machado M, Sun W, Jalal SI, Shah MA, Metges JP, et al: Safety and efficacy of pembrolizumab monotherapy in patients with previously treated advanced gastric and gastroesophageal junction cancer: Phase 2 Clinical KEYNOTE-059 trial. JAMA Oncol 4: e180013, 2018.

(i) $($ This work is licensed under a Creative Commons Attribution-NonCommercial-NoDerivatives 4.0 International (CC BY-NC-ND 4.0) License. 